\title{
Sustainable management of Prespa Lake
}

\author{
V. Popov ${ }^{1}$, T. Anovski ${ }^{2} \&$ R. Gospavic ${ }^{1}$ \\ ${ }^{1}$ Wessex Institute of Technology, Environmental and Fluid Mechanics, \\ Southampton, UK \\ ${ }^{2}$ Faculty of Technology and Metallurgy, \\ Department of Chemical and Control Engineering, Skopje, \\ Republic of Macedonia
}

\begin{abstract}
The Prespa Lake is on the border between Greece, Albania and Republic of Macedonia. The importance of Prespa Lake has been widely recognised by national and international bodies in the three neighbouring countries not only because of its natural beauty, but also because of its high biodiversity, including populations of rare water birds, like for example the Dalmatian pelican, as well as for its cultural values including Byzantine monuments. In recent years a decrease in water in the lake has been recorded. Though there have been several studies investigating the water level decrease, it has been impossible so far to conclude on the reasons behind this phenomenon. A research project has started recently supported by the NATO SfP programme which has as one of the main objectives to look into the cause behind the water level decrease, and also to suggest strategies for the water usage of the lake's watershed.
\end{abstract}

\section{Introduction}

Three lakes, Ohrid, Big Prespa and Small Prespa, are on the borders between Albania, Republic of Macedonia and Greece, see Figure 1. Galichica and Dry mountains separate the lakes. According to an existing hypothesis by Cvijic [1], water from the Prespa Lake, which is shared by the three neighbouring countries, is drained through the Galichica and Dry mountains into Ohrid Lake. In Figure 2 the lakes and the Galichica and Dry mountains are shown. Field research conducted first by Anovski et al. [2] and later by other scientists confirmed this hypothesis. 
The Lakes Big Prespa $\left(253.6 \mathrm{~km}^{2}\right)$ and Small Prespa $\left(47.4 \mathrm{~km}^{2}\right)$ are at $850 \mathrm{~m}$ asl. and are linked by a small channel with a sluice that separates the two lakes, see Figure 1. In the past, periodical oscillations of the lakes' level were in the range of one to three metres, depending on the amount of rain in the season. After the mid 80's, a steady decrease of the water level has been recorded that disturbs the ecological balance of the lake and the watershed area resulting in serious consequences for the fishing and tourist industry in the trans-boundary Prespa region. In addition to this, the industrial activities as well as the overuse of the herbicides in agriculture activities raised the problem of pollution of the water in the Prespa Lake.

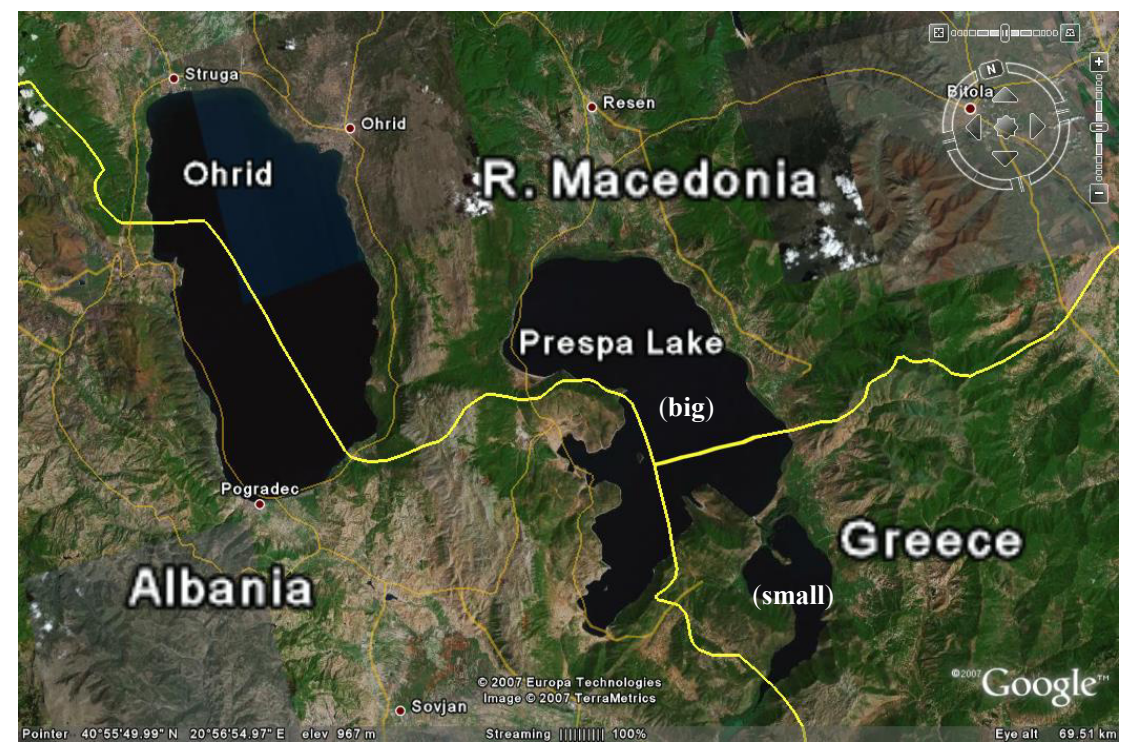

Figure 1: $\quad$ Ohrid, Big Prespa and Small Prespa lakes.

The Prespa Lake that is examined in the proposed programme constitutes an area of high ecological importance, because of its beauty as recreational places. On the other hand this is a site of economic significance, including agricultural, industrial and other activities, which use the water potential of this natural resource. For all of the above factors the sustainable development of the lakes and their surroundings is a field of particular interest.

The importance of Prespa Lake has been widely recognised by national and international bodies not only because of its natural beauty, but also because of its high biodiversity, including populations of rare water birds, like for example the Dalmatian pelican, a world vulnerable species, as well as for its cultural values including Byzantine monuments. 


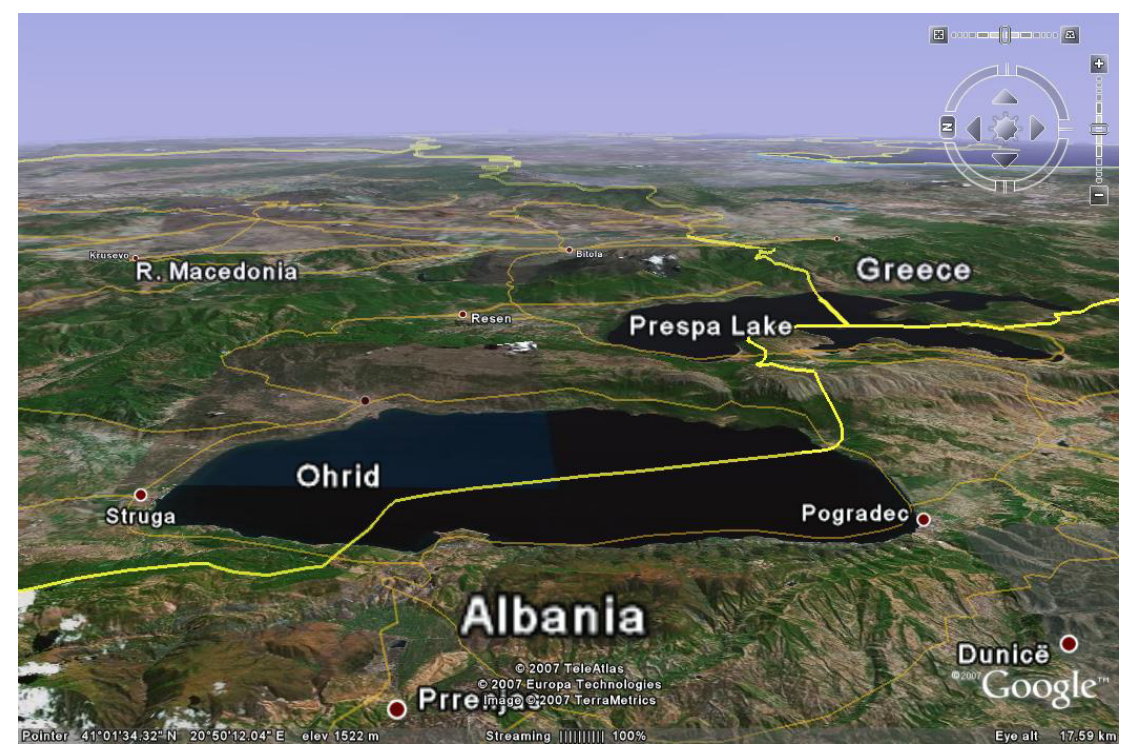

Figure 2: $\quad$ Ohrid and Prespa lakes with the Galichica and Dry Mountains in between.

State authorities of the three countries have enforced the protection status of Prespa through the use of national and international legislative means. A large part of the lakes and their catchment basin has been characterized as a National Park (Albania and Greece) or/and a Wetland of International Importance under the Ramsar Convention (Greece, R. Macedonia).

The willingness of the three governments to co-operate in order to promote the protection of all the Prespa area was corroborated on the $2^{\text {nd }}$ February 2000, when the Prime Ministers of Albania, Greece and the R. Macedonia issued a trilateral declaration recognising the international importance of the Prespa Lakes as well as the need for co-operation in order to promote conservation of its natural and cultural values.

One of the major environmental issues today that may, as well, have implications on the relation between the three neighbouring countries, is the question of global environmental degradation and increased shortages of renewable resources, especially international waters and watercourses, joint river basins and joint lakes. Increased pressure on the environment and natural recourses threatens the economic potentials of the countries. Hence, common response and action in the preservation of natural resources should be on the top of the agendas of all different regional initiatives and endeavors among the countries in the region. This calls for the development of instruments for managing of transboundary surface water and groundwater in the framework of ECE Helsinki Convention on the protection and Use of Transboundary Waters and International Lakes. This involves the collaboration for a regional characterisation of quantity and quality assessment and controls of water use and pollution emissions. 
The largest fraction of the population which live in the Prespa Lake's area depend on the lake itself. The lakes offer natural beauty that used to attract many tourists every year and they also offer suitable conditions for fish industry and agriculture. If the ecosystem of the lakes is disturbed, and there are indications that this is becoming reality, this may have disastrous consequence on the lives of a large part of the population in the area forcing many of them to migrate to other regions, which would create problems for those areas.

A joint project between five institutions from R. Macedonia, Albania, Greece and UK is currently funded through NATO Science for Peace and Security programme. The main objectives of the project are: (i) to understand the mechanism behind the water loss in the Prespa lake; (ii) to prepare recommendations for sustainable use of the water in the Prespa Lake watershed.

It is impossible to quantify the importance of this problem, since it involves the future of a natural resource of unique beauty and the future of the local communities whose economy largely depend on the lake.

\section{Results available from previous studies}

Recent research programmes that included research teams from the three neighbouring countries have established that the water level in the Big Prespa Lake has been lowering and the connection with the Small Prespa Lake has decreased (actually it is currently interrupted).

\subsection{Geology}

A great variety of rocks concerning their age, genesis, and lithology constitute this area. Intensive tectonic implications result in the modification of the primary rocks and in the formation of very different structures and of a heterogeneous relief picture. The following three main rock complexes are identified in the study area: metamorphic and intrusive rocks, carbonate rocks and terrigene rocks.

\subsection{Hydrogeology}

From the hydro-geological point of view, the rocks of Prespa-Ohrid area are classified as porous aquifers, karstic and fissured aquifers, fissured aquifers and practically non-aquiferous rocks.

\subsection{Quality of water}

Recent studies included water temperature, dissolved oxygen content, $\mathrm{pH}$, pesticides (HCB, PCB 138, $\gamma$-HCH, DDT, etc), different chemicals ( $\mathrm{Ca}, \mathrm{Mg}, \mathrm{Na}$, $\mathrm{K}, \mathrm{Fe}, \mathrm{Cl}, \mathrm{HCO}_{3}, \mathrm{NO}_{3}$, etc), and radioactivity (total- $\alpha$, total- $\beta$ and $\gamma-$ spectrometry) sampled at different points periodically for the duration of the research programme. The comparison of the recent data with the ones of the past years shows that there is a significant deterioration of the water quality. 


\subsection{Isotope data}

There is significant amount of data, collected by teams from the three neighbouring countries, on the $\mathrm{d}^{18} \mathrm{O}$ dating back to 1980 . This data can be used to estimate the retention time, to calibrate the numerical models for water movement in the Lake area and to trace any changes in the circulation of the water in the Lake.

\subsection{Hydrology and water balance}

There has been an exchange of meteorological data between the three neighbouring countries and cooperation between professional institutions in order to define the water balance of the Prespa Lake. The previous studies on water balance included: precipitation, evaporation, inflow and outflow by surface or underground mechanism in each of the three countries. These studies will be used as reference points for the future water balance estimations. However, the data from the three countries was never complete during a whole year, and this is the main reason that there was a discrepancy of $\approx 10^{8} \mathrm{~m}^{3}$ per year. The measurements during the proposed research programme will help a more accurate estimate to be obtained.

\subsection{Charting and profiling of the bottom of the Lake}

During the years 2000 and 2002 charting and profiling of the bottom of the Big Prespa Lake was carried out. The results showed two characteristic trenches-like structures on the lake's bed. One of the trenches is $7 \mathrm{~km}$ long, $0.9 \mathrm{~km}$ wide and $35 \mathrm{~m}$ deep on average, while the other one is $12 \mathrm{~km}$ long, $1.5 \mathrm{~km}$ wide and $23 \mathrm{~m}$ deep on average. The south part of the Lake showed an unexpected structure of the lake's bottom with sharp faults indicating strong tectonic movements. In the eastern part of the lake a large sedimentation area was identified, where several rivers inflow the lake. However, there is still plenty of data missing, and there is also some inconsistency, like using different equipment with different methodology in different parts.

\subsection{Artificial tracer experiment}

A preliminary artificial tracer experiment was carried out in order to obtain information on the dynamical parameters of the big Prespa Lake's water movement through the Galichica karstic massif. The experiment confirmed that an underground hydraulic connection between the Prespa and Ohrid lakes exists. At some observation points there was only one while at other points there were several peaks in the concentration of the observed tracer. This shows the complexity of the karstic system separating the two lakes. The results of this experiment will be used in order to improve the design of the next artificial tracer experiment, especially the sampling regime, which was not optimal during the first experiment and therefore the interpretation of the results was difficult. 


\section{The problem that will be addressed in the Project}

The main problem, which will be addressed in the NATO SfP Project is the decrease of the water level in the Prespa Lake and the mechanism behind it. In order an accurate water balance to be performed, measurements of precipitation, evaporation and direct river inflow into the lake during certain period of time, e.g., one year, must be conducted in the three neighbouring countries. Though each country performs such measurements, they were not systematically performed for a whole year in the three countries. This effectively prevents an accurate estimate of the water balance of the Prespa Lake.

In order that the dynamic parameters of the hydraulic communication between Prespa and Ohrid lakes through Dry Mountain and Galichica are established, tracer experiment will be conducted, which will include injection of tracers into sinkholes in the Prespa Lake and monitoring in the springs of the Ohrid Lake.

The following economic and social impacts in the region have been observed:

(i) $44 \mathrm{~km}$ of beaches on the Macedonian (FYRO) side have been disturbed because the Lake's shoreline falls and leaves muddy ground. Such situation is expensive to remediate since the shoreline is changing. There are approximately 7000 beds on the Macedonian part of Prespa Lake. In the past there were approximately 250,000 to 300,000 visitor/nights in the hotels per year, while in the past 7 to 8 years this number is at most 30,000 per year. The main reason for the decrease of the number of tourists is the decrease of the water level of the Lake.

(ii) As the water level in the Lake decreases, the water temperature in the Lake is changing as well. This affects the flora and fauna in the lake. The decrease in the fish production affects the fish industry.

(iii) Only about half of the wastewater released, produced by approximately 17,000 inhabitants on the Macedonian side, is pre-treated. As the amount of wastewater released remains more or less constant, except during the summer period when it is higher because of the visitors in the area, and as the water amount in the Lake decreases, the water quality deteriorates.

(iv) The Lake's water is used for agricultural purposes in all three neighbouring countries. It is estimated that within the Prespa Lake region there are 6,500 ha of agricultural land. On one hand the decrease of the water level increases the costs of irrigation since nowadays two pumps in line must be used, because of the lower level of the water, in order to provide the water for the agricultural fields. On the other hand, the water in the Lake during dry seasons may be decreasing by $1 \mathrm{~cm}$ per day due to combined effects of evaporation and irrigation. Many of the agricultural fields are placed in the catchment area of the Lake, which contributes that pesticides and fertilizers pollute the Lake. Since the intensity of the source of pollution is more or less constant and the amount of water decreases, the concentrations of polluting compounds in the Lake increase.

(v) The visual beauty of the Prespa Lake suffers due to the decreasing level of the water. 
Overall, the cumulative effects of the above-mentioned factors contribute towards ecologic and economic catastrophe of the Prespa Lake region.

Once the mechanisms behind the water level decrease are clearer, recommendations will be given of how to use the resources of the Lake in a more sustainable way.

\section{Possible causes for the decrease of the water level}

In Figure 3 the water level variation in the Prespa Lake is shown in the period 1956 to 2004. It can be seen that the water level decrease in respect to the highest level is approximately $8 \mathrm{~m}$. For a lake with an average depth of $15 \mathrm{~m}$ this can have a significant impact.

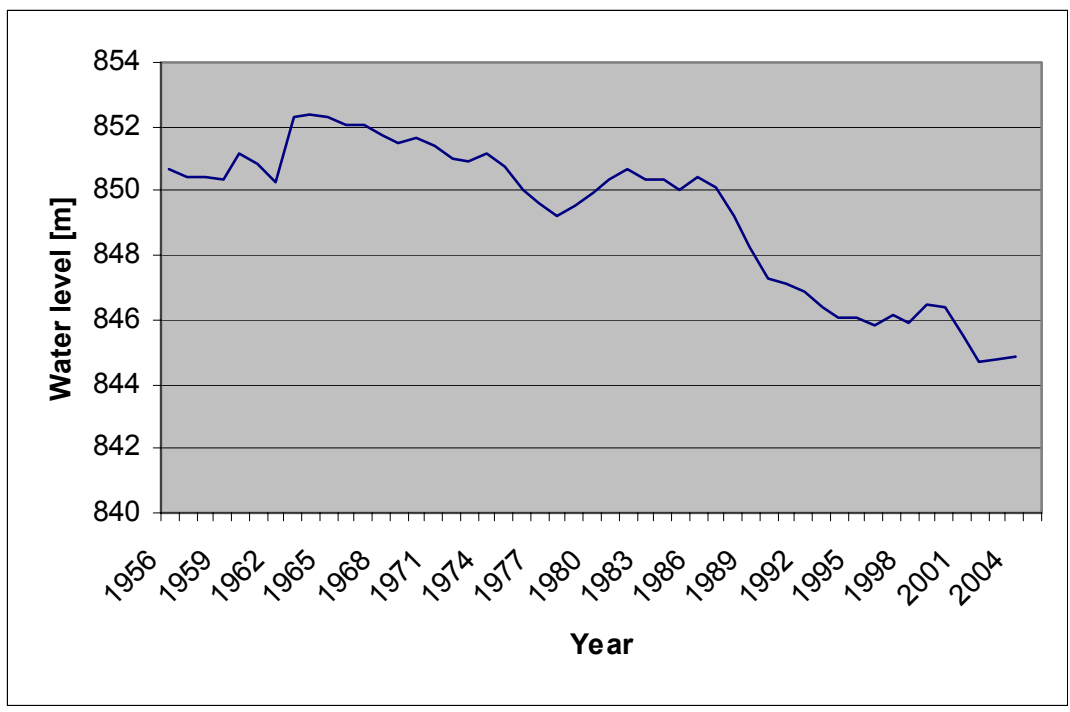

Figure 3: $\quad$ Change of water level of Big Prespa Lake from 1956 to 2004.

The possible causes for the water level decrease have been stated as [3]: (i) tectonic falling of the lake bottom; (ii) widening of underground channels connecting the two lakes; (iii) influence of meteorological parameters.

It is more likely that either (ii) or (iii) is the cause of the water level decrease in the lake, though a combination of (ii) and (iii) cannot be excluded. In the NATO SfP study another cause will be investigated, and that is the anthropogenic factor. Since there are agricultural activities in the area, this can also affect the water level in the lake, especially when there is a dry season. During a dry season more of the water from the lake's watershed, aquifer or direct extraction from the lake, will be used for agricultural purposes, exaggerating in this way the effects of a dry season on the lake's water level. 


\section{The research programme of the NATO SfP project}

The modeling part of the project will provide a link between the results acquired in the past and for the duration of the project. Though in the recent years a joint research programme between the three border countries has been conducted, the cause for this water-level drop is still not known, mainly because the data collected has not been processed in a systematic way and some of the state-ofthe-art computer simulation tools have not been used in the previous studies. The modeling part will help calculate the Lake's water budget, based on the surface river inflow, Lake water level, and meteorological data. In order to better understand the hydrological link between the Ohrid and Prespa lakes, some of the new developments in the field of flow in fractured porous media will be used [4].

The novel aspects of the project relate to the way to deal with water resources in karstic regions under the influence of the changing weather patterns. A full evaluation of the data available in the previous years combined with the data collected for the project duration will be used to estimate the implications on a complex system like the Prespa Lake where parameters like sinkholes, precipitation and evaporation, water inflow through rivers and streams and water use in agriculture must be taken into account.

\section{Conclusions}

The lakes Ohrid and Prespa (big and small) represent a unique and very complex water system, where the water from the Prespa lake leaks into the Ohrid lake through underground pathways. The recent steady water level decrease in the Prespa lake suggests that this beautiful lake which is part of this unique water system can be lost soon, unless the reason behind the water level drop is investigated and efficient measures are proposed for use of the water from the lake's watershed. One of the current efforts in saving the lake is the NATO SfP project, which has as its main objectives to discover the mechanism behind the water level decrease and to suggest strategies for the water usage of the lake's watershed.

It is speculated that the water level decrease could be due to: (i) changes in the hydrological link between the Ohrid and Prespa lakes (increase in the hydraulic conductivity of the aquifer linking the two lakes); (ii) change in weather conditions in recent years; (iii) change in water use by the local population for agricultural and industrial purposes. It is also possible that the cause for the water level decrease is due to combination of the above three possible causes.

The recently started NATO SfP project will include hydrometeorological measurements in the lake's watershed during one year in the three neighbouring countries, in order to accumulate enough accurate data to perform a comprehensive water balance, which should finally distinguish between the three possible causes mentioned above. Adequate models will be used in order to 
utilize the past and project's data in the most efficient manner. In addition an artificial tracer experiment will be conducted in order to better understand the dynamics of the hydrological link between the two lakes.

\section{Acknowledgement}

This work is supported by the NATO Science for Peace and Security programme (Project No. SfP 981116).

\section{References}

[1] Cvijic, J. (1906) Fundamentals of Geography and Geology of Macedonia and Serbia, Special Edition VIII+680, Belgrade.

[2] Anovski, T. et al. (1980), "A study of the origin of water in the St. Naum's Springs, Lake Ohrid”, FIZIKA - A Journal of Experimental and Theoretical Physics, Vol. 12 (S2).

[3] Anovski, T. (Ed.) (2001) Progress in study of Prespa Lake using nuclear and related techniques. IAEA Regional Project RER/8/008, Faculty of Technology and Metallurgy, Skopje, R. Macedonia.

[4] Peratta, A., Popov, V., (2006) 'A new scheme for numerical modelling of flow and transport processes in 3D fractured porous media', Advances in Water Resources, 29, 42-61.

[5] Samardzioska, T., Popov, V. (2005), 'Numerical comparison of the equivalent continuum, non-homogeneous and dual porosity models for flow and transport in fractured porous media', Advances in Water Resources, 28, 235-255. 